\title{
A community electrification project: Combination of microgrids and household systems feed by wind, PV or micro-hydro energies according to micro-scale resource evaluation and social constraints
}

\author{
Bruno Doménech ${ }^{12^{*}}$, Laia Ferrer-Martí ${ }^{13}$, Pau Lillo $^{4}$, Rafael Pastor $^{13}$, José Chiroque $^{5}$ \\ ${ }^{1}$ Institute of Industrial and Control Engineering (IOC), Universitat Politècnica de Catalunya (UPC), Av. Diagonal \\ 647, 08028 Barcelona, Spain. \\ ${ }^{2}$ Department of Management (DOE), UPC, Av. Diagonal 647, 08028 Barcelona, Spain. \\ ${ }^{3}$ Department of Mechanical Engineering (DEM), UPC, Av. Diagonal 647, 08028 Barcelona, Spain. \\ ${ }^{4}$ Engineering Without Borders - Catalonia (ESF), c/Murcia 24, 08001 Barcelona, Spain. \\ ${ }^{5}$ Practical Action, Av. Jorge Chavez 275, Lima, Peru. \\ Corresponding author $\left(^{*}\right)$ : bruno.domenech@upc.edu; 0034934016579.
}

\begin{abstract}
When electrifying isolated rural communities, usually standardized solutions have been implemented using the same technology at all the points. However these solutions are not always appropriate to the community and its population. This article aims to describe the technical design of the electrification system of the community of Alto Peru (in the region of Cajamarca, Peru), where the adequate technology was used at each area according to micro-scale resource evaluation and the socioeconomic requirements of the population. Specifically four technologies were implemented: wind microgrids in highlands, a micro-hydro power plant in the presence of a waterfall, a PV microgrid in a group of points sheltered from the wind and individual PV systems in scattered points with low wind potential. This project brought electricity to 58 households, a health center, a school, a church, two restaurants and two shops.
\end{abstract}

Keywords: wind-PV-micro-hydro energies; stand-alone electrification system design; micro-scale resource evaluation; social constraints; Peru.

\section{Introduction}

Early in the twenty first century, an estimated 1.3 billion people do not have access to electricity (IEA, 2013), especially in rural areas from developing countries (Kanagawa and Nakata, 2008). The contribution of energy, and particularly electricity, to meet the Millennium Development Goals of the United Nations Development Program has been widely demonstrated (DFID, 2002). Among other benefits, access to electricity helps: reducing eyesight and lungs illnesses (caused by smoke from kerosene lamps and candles), extending the daily productive hours, allowing children to study in the evenings, getting a better education through the use of new technologies at schools, increasing access to means of communication and improving health centers through the use of some medical devices or vaccines' refrigeration.

The conventional strategy for increasing access to electricity is to extend the national electric grid (Tenenbaum et al., 2014). However, due to the extensive and complex geography in many rural areas from developing countries as well as the dispersed nature of the existing villages, extending the national electric grid to reach all the rural households would be economically prohibitive (Wamukonya and Davis, 2001; Ferrer-Martí et al., 2012). In exchange, electrification systems based on the use of renewable energies are suitable to provide decentralized electricity to isolated communities around the world (Chaurey et al., 2004). These stand-alone systems are often cheaper than grid extension and use local resources avoiding external dependences, which in turn promotes the long-term sustainability of projects (Akorede et al., 2010). 
Among the available renewable technologies micro-hydro, photovoltaic (PV) and wind are the most widespread (Rolland and Glania, 2011). Usually, where a water resource is available, micro-hydro is the best option since it provides a continuous energy supply at a low cost per kilowatt hour (Coello et al., 2006). When this resource is enough, micro-hydro energy has been used successfully without combining with other technologies (Yadoo and Cruickshank, 2012). Alternatively, PV systems are usually chosen, although they are a more expensive option, and have been very used in recent decades as individual systems (Zahedi, 2006). For example, Nieuwenhout et al. (2001) analyze many PV projects in countries from Africa, Asia and Latin America, determining the advantages and limitations according to the context. Recently, wind power is gaining attention (Coello et al., 2006). In windy regions, wind systems can be cheaper than PV ones, for the same energy output. Moreover, wind turbines (WT) can be locally manufactured, helping the systems' maintenance (Leary et al., 2012). In most projects a turbine is installed at each consumption point without considering the detail of the wind resource. Some examples can be found in Mongolia, Nicaragua and Peru (Leary et al., 2012).

Hybrid systems that combine an adequate proportion of each local resource and provide more security of supply are one of the most recommended options (Amador and Dominguez, 2005; Rolland and Glania, 2011) since each technology complements to each other (Zhou et al., 2010). In particular hybrid systems that use PV and wind generators are increasingly been used (Deshmukh and Deshmukh, 2008). For example, Giatrakos et al. (2009) study a hybrid PV-wind system for a Greek island. Saheb-Koussa et al. (2009) study the best option of PV-wind systems for Algerian areas, according to climatic conditions and the topography. El-Shatter et al. (2006) design the size and management of a PV-wind system for a village in Egypt. Finally Nema et al. (2009) review several studies focusing the design, operation and control of PV-wind systems for remote areas. In a smaller amount, some projects consider a combination of micro-hydro, PV and wind technologies. For example, Bakos (2002) study the feasibility of a wind-hydraulic system for a farm on an island in Greece. Kenfack et al. (2009) design the size of a system combining micro-hydro and solar technologies. Bekele and Tadesse (2012) also incorporate the wind technology for sizing systems in areas with a limited hydraulic potential. Dorji et al. (2012) combine micro-hydro, PV and wind systems in Bhutan. Lastly Kumar Lal et al. (2011) show how designed systems are primarily fed by micro-hydro, PV or wind technologies depending on the time of the year. Other works propose selecting the most appropriate scenario among a set of predefined scenarios. In this sense, multicriteria decision-making aid tools have been widely used for energy planning (Pohekar and Ramachandran, 2004; Zhou et al., 2006). For example, Cavallaro and Ciraolo (2005) choose the best emplacement for WT in an Italian island considering techno-economic and environmental criteria. In exchange, the study at a local scale seems to be forgotten (Loken, 2007). One of the few researches in this research line is Henao et al. (2012) that develop the tool SURE, which studies different electrification technologies choosing the best one according to physical, financial, natural, social and human criteria.

However, the reviewed works do not analyze the detail of the appropriate technology for each part of the community using different design and decision techniques nor designing the electric distribution configuration (combining individual systems and microgrids) to adapt the system to the population characteristics. However, this is currently a subject under a great discussion among experts worldwide (Tenenbaum et al., 2014). This paper proposes to study the design of a Peruvian rural community overcoming the commented limitations. 
To our knowledge, Alto Peru's project (Peru) is a unique experience that electrifies a community through a combination of micro-hydro, $\mathrm{PV}$ and wind energies, and using individual systems and microgrids for the electric distribution. The main novelty of this project is that instead of using a single technology for all the population, the most appropriate option was installed at each part of the community, according to the demand, the location of the consumption points and the available resources. The operation and maintenance of the systems, which has proven to be a key issue for ensuring projects' sustainability (Rolland and Glania, 2011; Frearson and Tuckwell, 2013), was realized together through a community management model that was conceived specially for Alto Peru based on population's characteristics. Besides, the budget was a huge limitation during all the electrification process and many decisions were taken accordingly.

The community was composed by 65 consumption points, and their electrification was carried out between July 2009 and November 2010, in four stages: two wind microgrids for 13 households and the church; a micro-hydro power plant for the school and 4 households; a solar microgrid for the health center, the 2 restaurants and 2 households; and individual solar systems for the remaining 39 households and the 2 shops (Fig. 1). This paper aims to describe the real technical design process and how a particular solution was designed for each area of the community. At the end a technical evaluation of the systems' performance is realized.

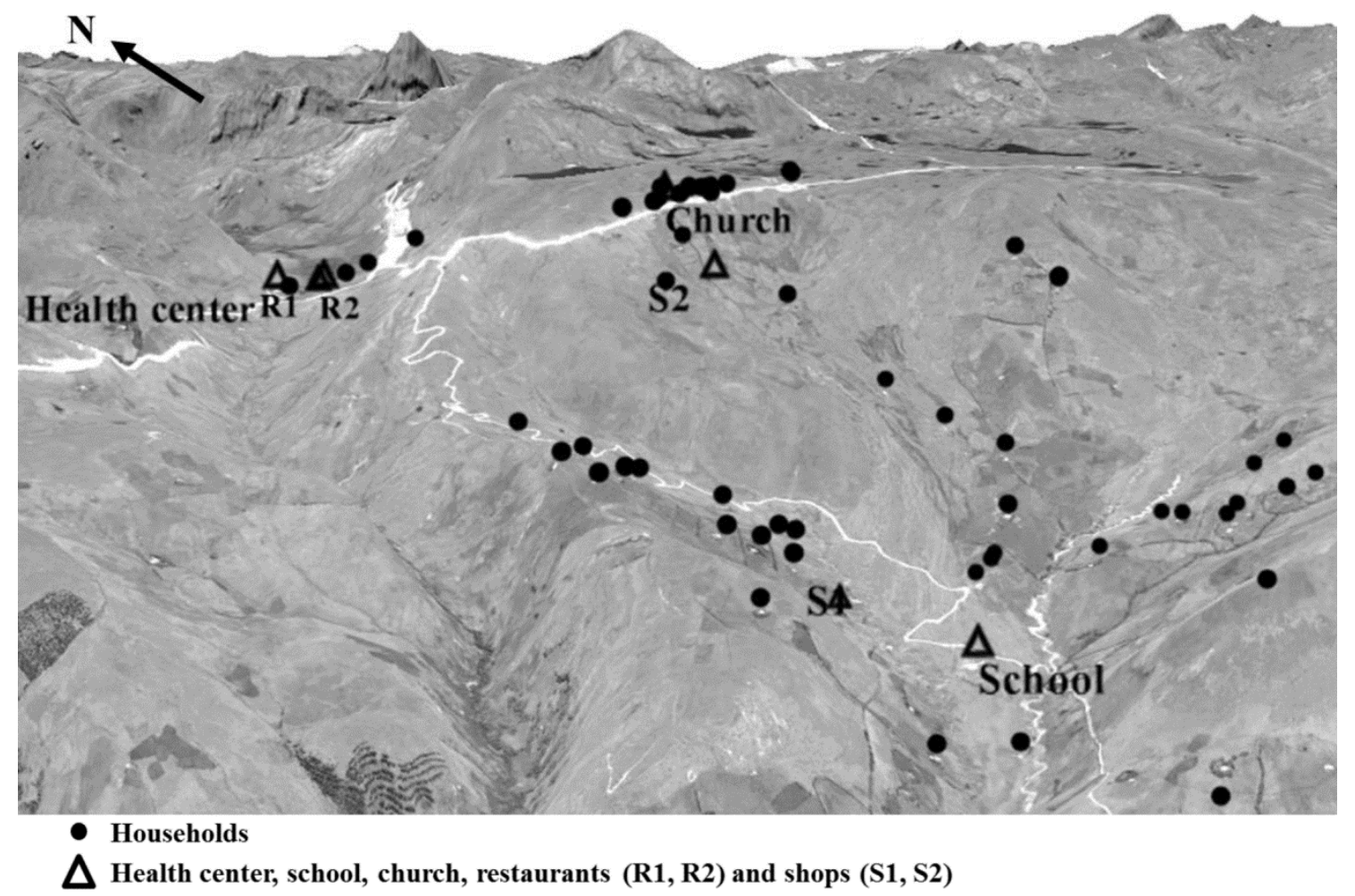

Fig. 1 - Location of the consumption points in the community of Alto Peru

The rest of the paper is organized as follows: Section 2 introduces the community of Alto Peru. The resource assessments are presented in Section 3. The technical description is detailed in Section 4. Section 5 presents the design of the whole electrification project. Section 6 evaluates the performance of the system. Finally, Section 7 summarizes main conclusions. 


\section{The community of Alto Peru}

In Peru around 6.5 million people do not have access to electricity, mostly in rural areas (MINEM, 2008). In this context, the NGOs Practical Action (PA), Peru, Engineering Without Borders (ESF), Spain, and Green Empowerment (GE), USA, with the support of the Research Group on Cooperation and Human Development of the Universitat Politècnica de Catalunya (GRECDH-UPC), Spain, developed from 2007 till 2011 the "Program for Rural Electrification and Access to Renewable Energies in the Andean Zone". The aim was to promote access to electricity in the region of Cajamarca, located in north of the Peruvian Andean highlands and which was one of the poorest areas in the country, with near than one million people living under the national poverty line, and which had the lowest electrification rate: $40.2 \%$ (INEI, 2007).

This work focuses on the electrification system of the community of Alto Peru. In May 2009, a socioeconomic diagnosis was realized to study the characteristics of the population (Ramirez and Mantilla, 2009). The tools used to collect information included socioeconomic surveys to each family, and interviews and focus groups with the local authorities, the local organizations and the representative residents. Main conclusions of the diagnosis are presented below: first the socioeconomic analysis is summarized and then the demand assessment is carried out.

\subsection{Socioeconomic analysis}

Alto Peru is located between 3500 and 4000 meters above the sea level (Fig. 2.a). The weather is cold, with temperatures hardly exceeding $10^{\circ} \mathrm{C}$. The rainy season goes from December to May, while the dry season goes from June to November and is accompanied by higher wind and solar resources. The topography is characterized by narrow valleys, large waved areas and gorges, and combines natural grass with rocky outcrops. The consumption points are spread over a wide land extension. Some of them are located in flatter areas while the others are placed in higher zones.

Initially 94 consumption points were identified with a total population of 345 inhabitants. One of the first tasks was to determine the real target points to electrify. Sometimes, some families did not want the electricity. Besides, a common case among population was the "mitayos": renters of a property who work and take care of the land in exchange for a tribute. In these cases the owner could not ensure somebody was going to live permanently and, therefore, the maintenance of the electric installations at the households was not ensured. Thus, the electrification of these points was discussed by the community. Finally it was decided that only the owners committing to take care of the maintenance of the systems throughout the lifecycle of the project would be included in the project. Otherwise, the electrification of the health center was also discussed. Alto Peru's population was attended by a health center administratively belonging to the neighbor community of Quebrada Honda. After the appropriate negotiations concluded its electrification was decided to be carried out. Finally 58 households, 2 shops, 2 restaurants, 1 health center, 1 school and 1 church, spread around $20 \mathrm{~km}^{2}$, were considered.

Family's incomes mainly came from cattle's rearing for milk sale and employs for the mining companies working in the surroundings. Agriculture and animals' rearing was mostly destined for self-consumption. The 2 restaurants lived off workers from the mining companies and the 2 shops supplied the community with essential items. Finally, standed out the lack or scarcity of services as safe drinking water, storm drains and electricity. 
Since the households of the community were very dispersed in a large area, the community administration was separated in two parts in 2008, the High and the Low Parts, aiming to ease population's organization. The High Part (rectangle in Fig. 2) was composed by 25 households, the church, the health center, the 2 restaurants and 1 shop, and was characterized by a higher concentration of the points and a higher wind potential. Meanwhile, the Low Part (outside the rectangle in Fig. 2) was composed by 33 households, the school and 1 shop, and presented less concentration of the points and a lower wind potential. At a social level, the relationship between the leaders from both parts was bad caused by disagreements during the realization of community activities in the past. Thus hypothetical coordination between them (in the case of a common electrification system) could be hard going. Besides, while in the High Part there was a good relationship between inhabitants, in the Low Part bad delimitations on the lands and bad shared out legacies led to conflicts between families.

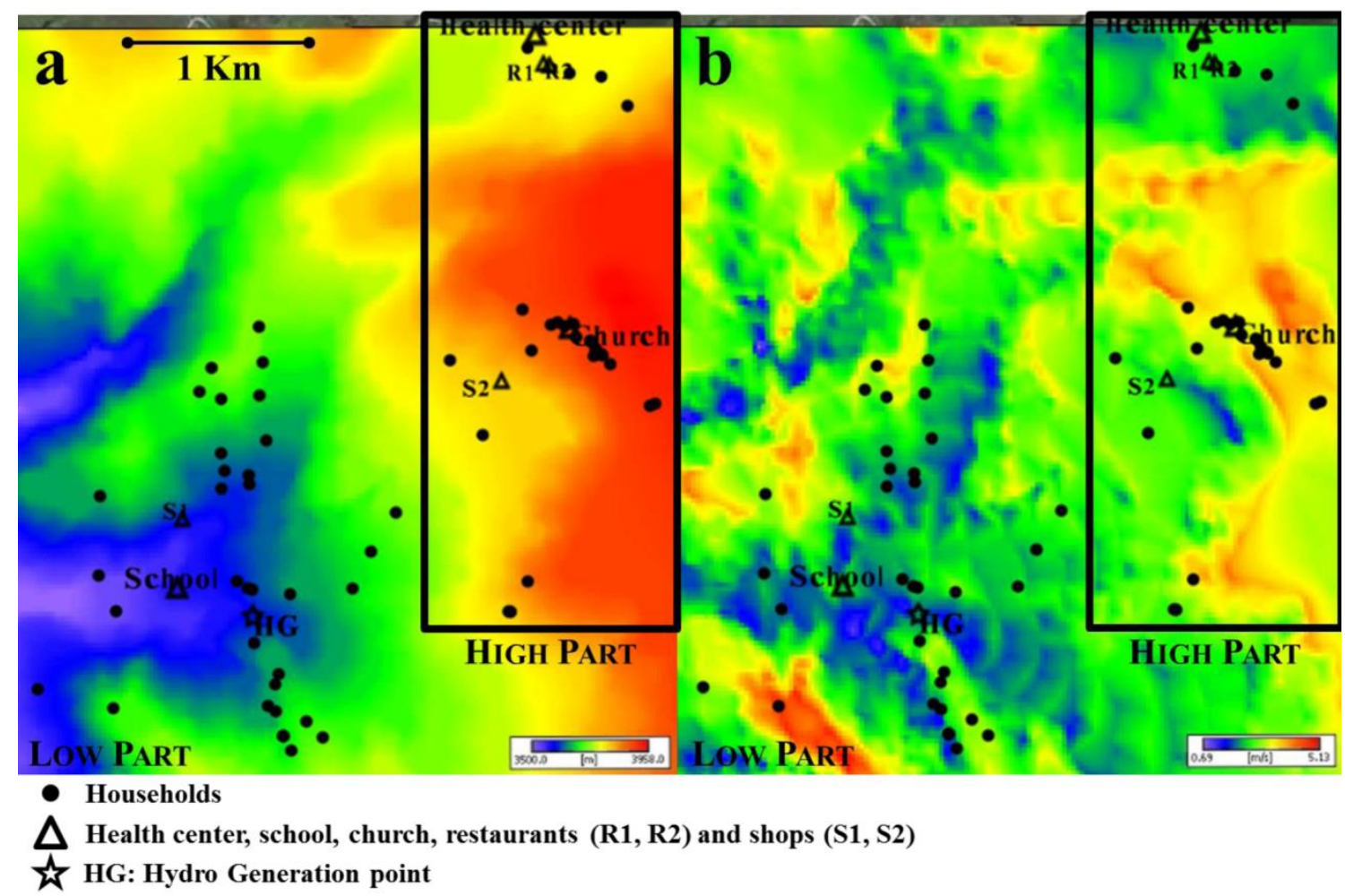

Fig. 2 - Elevation (a) and wind (b) maps of the community of Alto Peru

\subsection{Demand assessment}

The demand of the consumption points is a key issue when designing an electrification system. A demand overvalue can unnecessarily raise the project cost while a demand undervalue can renege on users' expectations (Frearson and Tuckwell, 2013). In both cases the project will probably fail shortly after its implementation. For that reason an accurate daily demand assessment was carried out. In particular the consumption habits of population, future demand increases and existing generation systems were examined. During this process, the end users involvement was sought in order to ensure that the established demand value responds to their real needs. Thus, an approximation of the electrical appliances used by population and their daily utilization could be established, leading to the finally determined demand values. 
In order to determine the demand of each considered point, the consumption habits were analyzed (Ramirez and Mantilla, 2009). As in most Andean communities, wood (77\%) and propane gas (23\%) were the most used resources for cooking. In exchange, candles (97\%) and gas lamps (3\%) were utilized for night lighting. From the entire population, $67 \%$ used radio receivers and flashlights supplied by dry batteries, $7 \%$ had small electric generators to charge cell phones and use some electric appliances (mainly TV or DVD), and $3 \%$ used batteries for the same purpose.

To complete the analysis, future hypothetical consumptions with the introduction of the electricity were studied (Ramirez and Mantilla, 2009). On the one hand, children expected extending their available hours for studying, while women forecasted to realize handicrafts with nighttime lighting. On the other hand, a few group of inhabitants showed interest on developing activities requiring a particular amount of electricity: installing a photocopier, a furniture shop, a local textile industry needing electric sewing machines and a local factory of milk derivate.

Else, the health center had a PV panel installed a few years ago (broken due to the lack of maintenance). The church and the school had their own electric generators, which were very rarely used due to the high fuel cost. Additionally some households had their own PV panels to load batteries or for domestic lighting, but many technical problems were identified (wrong electrical connections, high voltage drops, etc.) and most equipment/facilities were unusable.

From this information and considering possible consumption increases throughout the lifecycle of the electrification project, the demand was established. For this purpose, a list of the main electrical appliances that will be used (once the community is electrified) by each consumption point was carried out. For each appliance, an approximate power and daily utilization time were determined. Therefore, the next values were considered: at the households, the church, the restaurants and the shops an energy demand of around $280 \mathrm{Wh} /$ day, a power demand of around $200 \mathrm{~W}$ and an autonomy demand of 2 days; at the health center $975 \mathrm{Wh} / \mathrm{day}, 600 \mathrm{~W}$ and 2 days; and at the school $975 \mathrm{Wh} /$ day, $1000 \mathrm{~W}$ and 2 days.

\section{Resource evaluation}

This section details the analysis of the wind, solar and hydraulic resources. In the three cases a conservative study was done in order to ensure meeting the demand under the worst assumptions (the least resource month). Thus, the demand will also be met the rest of the year.

\subsection{Wind resource}

A wind resource atlas of the country realized in 2008 (Meteosim, 2008) showed that Cajamarca is one of the areas with the highest wind potential in Peru. In the first visits to Alto Peru a good wind potential was noted. In order to measure the wind direction and speed, an anemometer was installed near the church on a $10 \mathrm{~m}$ high tower, specifically in the highest zone of the community, in a flat terrain and with no obstacles to ensure a good quality in the measurements (Ranaboldo et al., 2014). Measures were taken every 10 minutes during more than one year and, thus, the least wind resource month (March) was identified; if the system meets the demand at this month it will also cover the rest of the year. Next, using specialized software and the contour map of the region, data was extrapolated from the anemometer to the surrounding area (Ranaboldo et al., 
2014). With this information and the power curves of the WT (wind turbines), the energy produced at each consumption point by each type of WT was calculated. Fig. 2.b shows the wind map for Alto Peru. When comparing Figs. 2.a (elevation map) and 2.b (wind map), a high wind resource can be observed in highlands and a much more limited resource in lowlands.

\subsection{Hydraulic resource}

In the surroundings of the community there are near than 280 lakes, the largest one having an area of $11 \mathrm{~km}^{2}$. This hydrological natural reserve supplies Alto Peru and the neighboring communities. In particular, water from the largest lake was used to irrigate pastures from the Low Part of the community. The only water resource allowing generating electricity was identified $500 \mathrm{~m}$ far from the school. To assess the water resource at this point, the water flow at the driest month (August) and the waterfall height were measured. Ensuring to meet the demand in the driest month, and considering a security factor (due to hypothetical water flow reductions in the future), the demand will also be met the rest of the year. Thus a water flow of $14 \mathrm{l} / \mathrm{s}$ and a height of $31.73 \mathrm{~m}$ were determined in order to implement a hypothetical micro-hydro power plant. The entire micro-hydro power plant was designed to ensure both values throughout the entire year.

\subsection{Solar resource}

The solar resource was assumed to be uniform in all the community (Gueymard and Wilcox, 2011). This resource was estimated through the Peak Solar Hours (PSH), which is defined as the time, in hours per day, of a hypothetical constant irradiance of $1000 \mathrm{~W} / \mathrm{m}^{2}$. The temperature has also an influence on the panels' efficiency. In order to carry out a conservative analysis, the PSH and the temperature data were gathered for each month of the year. The NASA climate database offers both data since 1983 until 2005 (NASA, 2012). Therefore the monthly mean energy generated by a PV panel was calculated and the lowest potential month (February) was identified. In Alto Peru a PSH of 4.61 (i.e. 4.61 hours of sun per day at $1 \mathrm{~kW} / \mathrm{m}^{2}$ ) and a temperature of $7.99^{\circ} \mathrm{C}$ were determined for this month.

\section{Technical assessment}

The scheme of a stand-alone rural electrification system based on wind-PV-micro-hydro energies and with electric distribution through microgrids or individual systems is shown in Fig. 3. The electricity is generated by WT, PV panels and/or micro-hydro power plants. At a same generation point a single technology (in which case there will only be the corresponding branch in Fig. 3), two or the three technologies can be implemented. Moreover a controller is needed: for the wind technology to transform AC into DC and protect batteries from overcharges and deep discharges, for the PV technology to protect batteries from overcharges and deep discharges and to transform the $18 \mathrm{~V}$ generated current to $12 \mathrm{~V}$ current, and for the micro-hydro technology to adjust the generation to the consumption. The electricity is then stored in batteries, which must have enough capacity to meet the demand during several days without generation. Batteries are only needed for wind and PV technologies due to their resources' variability. Finally, inverters transform DC $(12 \mathrm{~V})$ power leaving batteries into $\mathrm{AC}(220 \mathrm{~V})$, which is more suitable for most electrical appliances. 


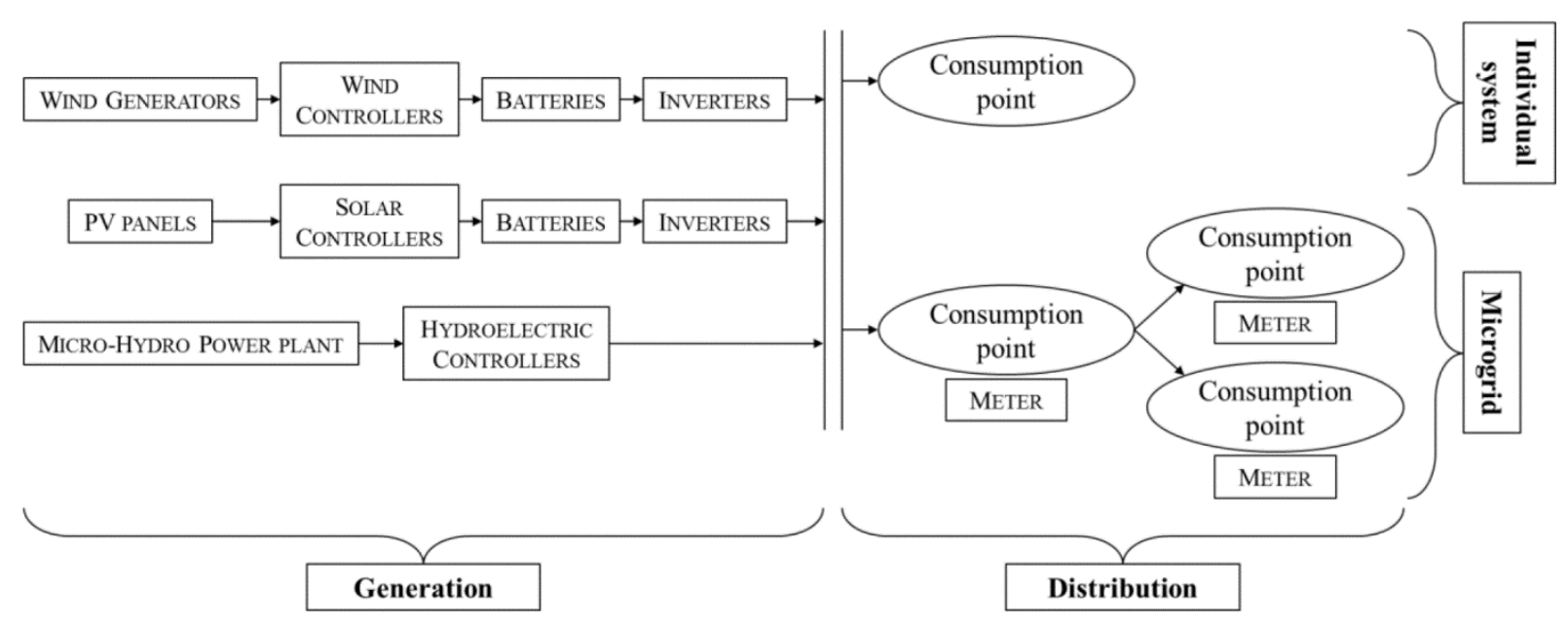

Fig. 3 - Scheme of a micro-hydro-PV-wind electrification system with distribution through a microgrid

Electricity is then distributed to the consumption points. This distribution can be done through individual systems (a generation point supplies to one consumption point) or through microgrids (a generation point supplies to more than one consumption point). Microgrids have a radial scheme (form of a tree as in Fig. 3), usually used in rural areas from developing countries (Lambert and Hittle, 2000). Finally, the points fed by a microgrid usually have a meter to control their consumption.

A market study was carried out in order to identify the equipment available in the region of the community and to determine their mainly technical and economical characteristics:

- Wind turbines (4 types). Maximum power: 300, 1200, 1750 and 3500 W. Cost: \$974, \$2737, $\$ 4105$ and $\$ 5131$; including the support tower.

- Wind controllers (4 types). Maximum power: 420, 1440, 1800 and $3600 \mathrm{~W}$. Cost: \$165, $\$ 285, \$ 342$ and $\$ 513$.

- Solar panels (4 types). Maximum power: 50, 75, 95 and $150 \mathrm{~W}$. Cost: \$451, \$636, \$821 and $\$ 1000$; including the support structure.

- Solar controllers (4 types). Maximum power: 50, 75, 95 and $200 \mathrm{~W}$. Cost: \$67, \$81, \$95 and $\$ 125$.

- Micro-hydro power plant (4 types). Power: $2000 \mathrm{~W}$. Type of turbine: Michell-Banki, Pelton, Turgo and Francis. Cost: \$2600, \$3000, \$3800 and \$4600.

- Micro-hydro controller. Maximum power: $2000 \mathrm{~W}$.

- Batteries (4 types). Capacity: 1500, 1800, 2400 and 3000 Wh. Cost: \$225, \$246, \$292 and \$325. Efficiency: $85 \%$. Discharge factor: $50 \%$. The same efficiency and discharge factor were considered for all the types of batteries.

- Inverters (4 types). Maximum power: 300, 1200, 2000 and $3000 \mathrm{~W}$. Cost: \$377, \$1200, $\$ 1800$ and \$2300. Efficiency: $85 \%$. The same efficiency was considered for all the types of inverters.

- Meters (1 type). Cost: $\$ 50$.

- Wires (3 types). Resistance: 2.71, 2.15 and $1.71 \Omega / \mathrm{km}$. Cost: $\$ 4.9, \$ 5.1$ and $\$ 5.25 / \mathrm{m}$. Efficiency: $90 \%$. 


\section{Project design}

In most stand-alone rural communities standardized electrification solutions are usually implemented without studying in detail if the solution is suitable to the socioeconomic aspects of the beneficiaries. However, in general, and more specifically in Alto Peru, these standardized solutions would not have been appropriate:

- The 65 consumption points of the community to be electrified were spread over a large region with a great variability on resources. Consequently the use of only one technology to cover all the community, as usually done, would not have been the most appropriate option. In exchange the adequate technology according to the available energy resources of each area was more efficient: in the presence of a waterfall micro-hydro energy, in highlands wind energy and in lowlands sheltered from the wind, solar energy.

- Scattering among consumption points was very variable: there was high concentration in some zones and high dispersion in others. Moreover the administrative organization of the population was complex: political divisions between parts, social conflicts between families; turning a hypothetical common organization a real challenge. Therefore the electrification system required to combine microgrids and individual systems in order to extend as much as possible the social benefits of microgrids but adapting the electric distribution to the socioeconomic specifications of the population.

In this way, the project was carried out in four stages:

- Stage 1, wind microgrids (Fig. 4). In July 2009 four 1200 W WT were installed to supply 13 households and the church through two microgrids of 8 and 6 users.

- Stage 2, micro-hydro power plant (Fig. 4). In August 2010 a $2000 \mathrm{~W}$ hydroelectric power plant was installed to supply the school and 4 households.

- Stage 3, PV microgrid (Fig. 4). In October 2010 eight $95 \mathrm{~W}$ PV panels were installed to supply the health center, the 2 restaurants and 2 households through a single microgrid.

- Stage 4, individual PV systems (Fig. 4, points not included in Stages 1, 2 or 3). In November 2010 forty-one $95 \mathrm{~W}$ PV panels were installed to supply the remaining 39 households and the 2 shops, through individual systems.

Table 1 summarizes the consumption points electrified at each stage and Fig. 4 shows their location in the wind map. Next, the technical design of each stage is described in detail.

Table 1 - Consumption points electrified at each stage

\begin{tabular}{|c|c|c|c|c|}
\hline & \multirow{2}{*}{ Technology } & \multicolumn{3}{|c|}{ Beneficiaries } \\
\hline & & Households & Institutions & Total \\
\hline Stage 1 & Wind microgrids & 13 & 1 (church) & 14 \\
\hline Stage 2 & Micro-hydro power plant & 4 & 1 (school) & 5 \\
\hline Stage 3 & PV microgrid & 2 & $\begin{array}{c}1 \text { (health center) } \\
2 \text { (restaurants) }\end{array}$ & 5 \\
\hline Stage 4 & Individual PV systems & 39 & 2 (shops) & 41 \\
\hline & Total & 58 & 7 & 65 \\
\hline
\end{tabular}




\subsection{Stage 1 - Wind microgrids}

To our known Alto Peru was one of the first stand-alone rural electrification projects in Peru utilizing wind energy. The use of this technology was strategic, in order to promote micro-scale wind projects throughout the country. Therefore only the highest wind potential area was initially considered. As shown in Fig. 2.b, the High Part has a higher wind potential and is characterized by yellow-to-red tones, while the Low Part is characterized by green-to-blue tones. In particular the study firstly focused on the consumption points with the highest wind resource, i.e. 24 households, a shop (S2) and the church.

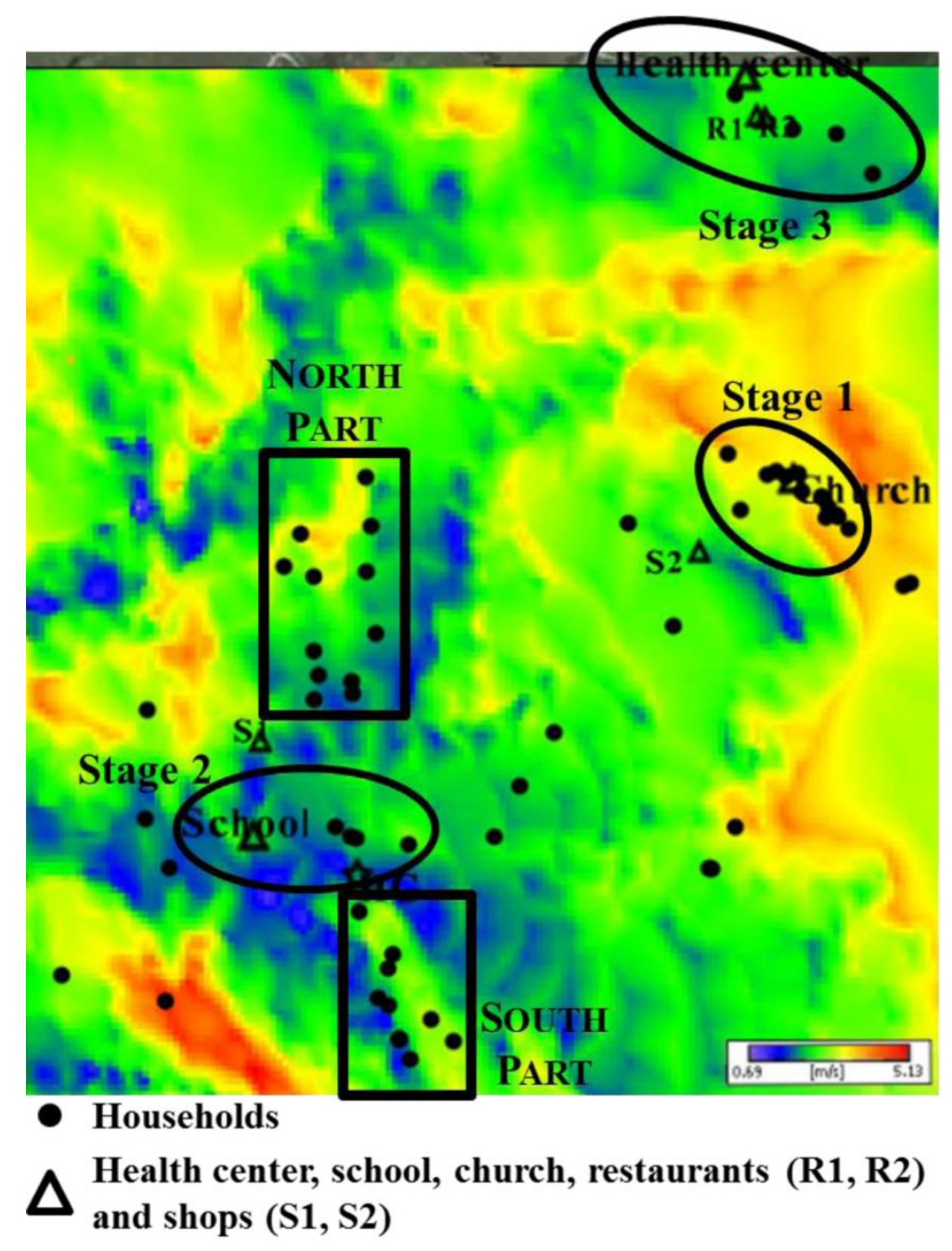

Fig. 4 - Consumption points electrified at each stage

To design the electrification system, a mathematical model minimizing the initial investment cost and considering the wind technology, the detail of the energy and power demands, and technical constraints related to the equipment was used (Ferrer-Martí et al., 2011). As a result, the model obtains the location and size of all the equipment, combining individual systems and microgrids. The solution for this study was: two main microgrids ( 8 and 6 users) in the main group of consumption points, and smaller microgrids (between 2 and 3 users) in the remaining points (Ferrer-Martí et al., 2013). 
The promoters of the electrification project decided to start by the 14 consumption points of the two main microgrids, which are placed in one of the highest wind potential areas (Fig. 4) and near to the access road to the community, making the materials' transport easier and cheaper. For these 14 points (13 households and the church) a two-step detailed analysis of the electrification system was realized. First several electrification options were generated (each one suitable to specific socioeconomic aspects of the population) and then the most appropriate option was selected. Meanwhile, the electrification of the remaining 12 consumption points was decided to be studied afterwards, in Stage 4.

\section{Generation of electrification options}

The considerations taken into account for generating the electrification options were extracted from interviews with the stakeholders involved in the project, and carried out in several meetings during the design process. In particular the political institutions (in charge of the systems management once implemented the project), some sociologists from PA and GE (who realized the socioeconomic analysis), some technicians from PA and ESF (with a great experience in rural electrification projects) and the own population participated. Thus a wide range of points of view were represented. The aim was to identify the features that could influence the design appropriateness and so that should be studied. Specifically, participants were asked about aspects such as the electrical needs of population, the land availability to install the equipment and the equipment availability. The following aspects were finally considered (Domenech et al., 2012):

- Energy, power and autonomy demand scenarios. Due to discontinuities and economies of scale in the equipment, small changes in the demand can lead to big changes in the cost or the energy supplied. Consequently, two demand scenarios were studied. The low scenario (energy and power demands determined in Section 2) covers basic lighting and telecommunications consumptions. The high scenario (+50\% demand in relation to the low scenario) allows, in addition, developing small productive activities and/or enjoying some domestic comforts. No variations for the autonomy demand were analyzed.

- Impose a space limitation vs. never impose it. Available space around the consumption points (where generators can be installed) is generally limited since is required for livestock or agriculture. Therefore a maximum of 2 generators can be installed at a same point could be interesting in order to avoid an excessive land occupation.

- Considering the two smaller types of WT vs. considering the four types of WT (Section 4). In Peru and specifically in the region of Cajamarca, a great effort has been carried out in the last years to promote the development of a local micro-wind technology. Therefore, considering the use of only the two smaller types of WT (which are locally manufactured) reinforces this local technology, indirectly helping to create local jobs. In exchange, considering the four types of WT, i.e. combining the two smaller types with the two bigger types (which need to be imported) can allow reducing costs due to the least ratio cost / energy generated of the bigger types (because of the economies of scale). 
Using the design tool described previously (Ferrer-Martí et al., 2011) eight electrification options were generated as a result of combining the two demand scenarios, the imposition (or not) of a space limitation and the use of the two smaller types of WT or the four types of WT. Moreover two additional options were generated installing individual wind systems at each consumption point, for the two demand scenarios. Table 2 shows the detail of the electrification solutions in four rows: the number of each type of the four types of WT, the cost of the solutions, the number of microgrids and its size (amount of users) and the number of individual users.

Table 2 - Main characteristics of the electrification options generated in Stage 1

\begin{tabular}{|c|c|c|c|c|c|c|c|c|c|c|}
\hline & \multirow{2}{*}{\multicolumn{5}{|c|}{ Low scenario $(280 \mathrm{Wh} /$ day; $200 \mathrm{~W})$}} & \multirow{2}{*}{\multicolumn{5}{|c|}{ High scenario (420 Wh/day; $300 \mathrm{~W})$}} \\
\hline & & & & & & & & & & \\
\hline & \multirow{2}{*}{ Indiv. } & \multicolumn{2}{|c|}{ No space limit } & \multicolumn{2}{|c|}{ Space limit } & \multirow{2}{*}{ Indiv. } & \multicolumn{2}{|c|}{\begin{tabular}{|l|} 
No space limit \\
\end{tabular}} & \multicolumn{2}{|c|}{ Space limit } \\
\hline & & 2 WT & $4 \mathrm{WT}$ & 2 WT & $4 \mathrm{WT}$ & & $2 \mathrm{WT}$ & $4 \mathrm{WT}$ & 2 WT & $4 \mathrm{WT}$ \\
\hline $\begin{array}{l}\text { Number wind turbines } \\
\mathbf{3 0 0 , 1 2 0 0 , 1 7 5 0 , 3 5 0 0 ~ W}\end{array}$ & $22,0,0,0$ & $2,3,0,0$ & $0,0,0,1$ & $0,4,0,0$ & $0,0,0,1$ & $26,1,0,0$ & $1,5,0,0$ & $0,1,0,1$ & $0,6,0,0$ & $0,1,0,1$ \\
\hline Cost [\$] & 33420 & 20238 & 15008 & 21836 & 15008 & 41417 & 27772 & 20753 & 31435 & 20753 \\
\hline $\mathrm{N}^{0}$ microgrids (users) & 0 & $1(13)$ & $1(14)$ & $1(8) ; 1(6)$ & $1(14)$ & 0 & $1(14)$ & $1(14)$ & $2(5) ; 1(4)$ & $1(14)$ \\
\hline Individual users & 14 & 1 & 0 & 0 & 0 & 14 & 0 & 0 & 0 & 0 \\
\hline
\end{tabular}

Table 2 shows the use of microgrids allowed a significant reduction on the cost of the solutions, which could be more or less emphasized depending on whether other considerations were included or not. Additionally, the use of the four types of WT reduced the cost when comparing to the use of only the two smaller types. Indeed, due to the economies of scale, the more powerful the equipment was the less cost per unit of energy generated. So, for the low demand scenario cost diminished among $45.5 \%$ and $34.8 \%$, and for the high demand scenario among $51.5 \%$ and $33.8 \%$, depending on whether the space limitation was included or not, respectively. Finally, limiting the number of WT can be installed at a point had an influence only when using the two small WT. The cost slightly increased and more but smaller microgrids were implemented.

\section{Selection of the most appropriate electrification option}

To complete the design of the system, results were presented to a group of technical and social experts from the NGOs PA and ESF. They all knew the community in detail, so they could compare the advantages and limitations of each electrification option, considering the social detail of the population. They firstly highlighted that solutions with microgrids were cheaper and could promote community's organization, being very positive for future development projects (sanitation, drinking water, etc.). Secondly they concluded the higher cost when increasing the demand from the low to the high scenario was not compensated by the benefits of the additional amount of energy. Finally they proposed to use only the two smaller types of WT, to promote the local wind technology, although the cost of these solutions was slightly more expensive. So, two microgrids of 8 and 6 users were implemented, each one supplied by two 1200 W WT, with a total cost of $\$ 21836$.

\subsection{Stage 2 - Micro-hydro power plant}

When Stage 1 ended, the project stopped for a year approximately due to budget limitations. When the activities started again, the study firstly focused the school because the population showed a great interest on providing access to the new technologies for the children. For this purpose in the resource assessment (Subsection 3.2) a waterfall was identified. In order to 
implement a micro-hydro power plant, an agreement with the land's owner was reached, establishing the irrigation periods and the electric generation periods throughout the day. The aim was to avoid the electric supply during the school hours disturbs the owner's use of water for agriculture, and vice versa. Thus, considering the water flow and the waterfall height from Subsection 3.2, the power generated by the micro-hydro power plant was calculated, which resulted $2000 \mathrm{~W}$, taking into account an efficiency of around $50 \%$ when transforming from potential energy into electrical energy (Coello et al., 2006). The micro-hydro power plant was initially conceived to supply electricity to the school exclusively. However the school power demand was less than the micro-hydro power plant capacity, so the remaining power was used to electrify some households. Taking into account the power demand of the households and a safety margin, the nearest four households were electrified. Finally, it was decided a $2000 \mathrm{~W}$ MichellBanki turbine was installed because, as well as being the cheapest among the available turbines, its simplicity allowed on site repairs in case of breakdown, while other types of turbines as Pelton or Francis, are technically more complex and usually require specialized technicians for their repairs. Moreover, a $2000 \mathrm{~W}$ hydraulic controller was installed. The total cost of the micro-hydro power plant was $\$ 13341$.

\subsection{Stage 3 - Solar microgrid}

The next stage focused on the health center, whose electrification was essential for giving access to a better sanity service: nighttime lighting for urgent interventions, a fridge for refrigerating the vaccines, etc. Besides, the 2 restaurants and two households also located in the northernmost area of the community were included in this stage. In the area there were no waterfalls and the wind potential was low (Fig. 4), so only PV technology was considered. Once the technology was chosen, the electric distribution system was designed. As seen in Fig. 4, the five consumption points (the health center, the 2 restaurants and the 2 households) were very close to each other, so the possibility of electrifying them through a single microgrid was conceived. This configuration entails some social benefits as the possibility to punctually increase the consumption of one user, what could be very interesting for the health center in case of an emergency or for the restaurants. Besides, as stated in Section 2, no social conflicts were identified between users in this area, so coordination between them did not suppose any problem. In conclusion all the users were electrified through a PV microgrid. To cover the demand eight $95 \mathrm{~W}$ PV panels were installed. The total cost for the solar microgrid was \$12699.

\subsection{Stage 4 - Individual solar systems}

When analyzing the remaining 41 consumption points, two clusters were identified and the promoters of the electrification project decided to first focus on them: the North Part and the South Part composed by 13 and 9 households, respectively (Fig. 4). In these 22 points, there was a bad relation between families and a medium dispersion. Thus neither microgrids nor individual systems were clearly the appropriate electrification options and a combination of both options was studied. For this purpose a two-step design process (as in Stage 1) was carried out: first several electrification options were generated and then the most appropriate was selected. 


\section{Generation of electrification options}

The considerations taken into account for generating the electrification options were extracted from interviews with the stakeholders involved in the project (the political institutions, some sociologists, some technicians and the own community). In this stage the studied aspects were different than in Stage 1, since the particular characteristics of this area were not the same (mainly bad relationships between users, medium dispersion of the consumption points and low wind potential). Particularly, participants were asked about features such as the technology preferences, the electrical needs of population, the community organization around the electrification project and the equipment failures. The following aspects were finally considered (Domenech et al., 2012):

- Wind technology vs. PV technology. The options of generating the electricity using wind turbines or PV panels were examined, since wind technology can be cheaper for higher demands (microgrids) while PV technology was more continuous in the area.

- Energy, power and autonomy demand scenarios. A low scenario (with the energy, power and autonomy demands determined in Section 2) was considered to cover usual lighting and telecommunications consumptions. A high scenario $(+20 \%$ of the energy and power demands, and $+50 \%$ of the autonomy demand than the low scenario) was also evaluated.

- Meters only in microgrid users vs. meters at all the consumption points. On the one hand, the installation of meters only in microgrid users allows saving costs, but an electricity tariff according to the consumption is established for microgrid points while a standard tariff is established for individual points. Therefore users with different consumptions could pay the same tariff (or vice versa). On the other hand, the installation of meters at all the consumption points is a more expensive option, but allows establishing a unique tariff according to the consumption for all the users.

- Individual electrification vs. microgrid electrification vs. combination of individuals and microgrids. On the one hand, given the benefits of microgrids in front of individual systems, the option of electrifying all the users through two microgrids (one for the North Part and one for the South Part) was examined. On the other hand, due to the existing social conflicts between families in the target area the option of electrifying all the users through individual systems was considered. Moreover, the combination of both options was evaluated in order to determine the possible cost savings.

- Impose a minimum number of generation equipment vs. not imposing it. A minimum of 2 generation equipment at each generation point was investigated in order to ensure if one fails, at least, another one will still supply the electricity.

For generating the electrification options, a mathematical model (Ferrer-Martí et al., 2013) was used, that allows considering the wind or the PV technologies in the design of the electrification systems. A total of 48 electrification options were generated (obtaining the electrification solutions and their respective costs) as a result of combining all the proposed variations. 


\section{Selection of the most appropriate electrification option}

In Stage 1 only ten options were generated and could be presented to a group of experts to select the most appropriate one. However in this stage 48 options were generated, so to ease the decision-making, this number was reduced before presenting results to the group of experts (Nijkamp et al., 1990). Moreover, the North Part and the South Part were characterized by many social conflicts and a medium dispersion of the consumption points, so the selection of the most appropriate electrification option involved a great amount of non-technical considerations. In this sense, the experience of the decision making from Stage 1 and the acquired knowledge on multicriteria decision-making processes were used to select a reduced set (5 options) among the 48 electrification options. The process was: first a group of evaluation criteria was defined, then the importance of each one was determined and finally each electrification option was evaluated in relation to each criterion (Wang et al., 2009). Thus an overall weighted score was calculated, options were classified accordingly and the 5 top-ranked were presented to the group of experts.

One of the main problems when evaluating rural electrification systems is to find a set of criteria allowing assessing the options from a wide range of points of view, both qualitatively and quantitatively. For this purpose, a meeting with a group of experts from the NGOs PA and ESF was realized and the social and technical criteria were defined (Table 3). Next, the criteria were weighted by the experts (a value was associated to each one representing its importance regarding to the others), basing their decisions on the characteristics of the community (Table 3 ). Then each electrification option was evaluated according to each criterion: following standardized indicators a value from 1 to 10 was associated to each option representing how little or much it meets each criteria. Finally the weighted sum was calculated for each option and the options were classified accordingly. Table 4 shows the main characteristics of the 5 top-ranked options.

Table 3 - Evaluation criteria and their corresponding definitions and weights for the community of Alto Peru

\begin{tabular}{|c|c|c|c|}
\hline & Criteria & Definition & $\begin{array}{l}\text { Weight of } \\
\text { the criteria }\end{array}$ \\
\hline \multirow{7}{*}{ } & Ease of management & Ease to manage the electrification system inside the families and between them. & 3 \\
\hline & Equity & Equality in the amount of electricity supplied to each family. & 7 \\
\hline & Economy & Economic effort of each family to pay the tariff for the electricity. & 7 \\
\hline & Household benefits & Improvements in the quality of life of the families and their incomes. & 5 \\
\hline & Community services & Electrification of the community services (school, health center, church). & 0 \\
\hline & Productive activities & Generation of local jobs thanks to the development of productive activities. & 2 \\
\hline & $\begin{array}{l}\text { Impact on local } \\
\text { resources }\end{array}$ & Covered land by the installed equipment & 1 \\
\hline \multirow{7}{*}{ 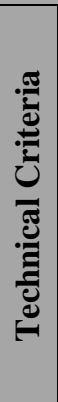 } & Economy & Initial investment and operation and maintenance costs. & 10 \\
\hline & Supplied energy & Amount of energy and power supplied to each family. & 5 \\
\hline & $\begin{array}{l}\text { Continuity of the } \\
\text { resources }\end{array}$ & Reliability of the utilized energy resources and autonomy of the batteries. & 5 \\
\hline & Flexibility & $\begin{array}{l}\text { Ease to expand the scope of electrification, by the adhesion of new users or by } \\
\text { increasing punctually the consumption. }\end{array}$ & 2 \\
\hline & Local replacement & Closeness of the assistance to repair failures in the equipment. & 3 \\
\hline & Local manufacturing & Closeness of the places where the equipment are manufactured. & 2 \\
\hline & Safety & System reliability in front of failures in the equipment due to breakdowns. & 6 \\
\hline
\end{tabular}


Table 4 - The 5 top-ranked electrifications options in Stage 4

\begin{tabular}{|l|c|c|c|c|c|}
\cline { 2 - 6 } \multicolumn{1}{c|}{} & PV indiv & PV mgrid & $\begin{array}{c}\text { PV mgrids \& indiv } \\
\text { (all meters) }\end{array}$ & $\begin{array}{c}\text { PV mgrids and indiv } \\
\text { (mgrid meters) }\end{array}$ & Wind mgrid \\
\hline Demand: & Low & Low & Low & Low & High \\
Energy [Wh/day] & 280 & 280 & 280 & 280 & 336 \\
Power [W] & 200 & 200 & 200 & 200 & 240 \\
Autonomy [days] & 2 & 2 & 2 & 2 & 3 \\
\hline Technology used & Solar & Solar & Solar & Solar & Wind \\
\hline Mgrids, indivs or both? & Indivs & Mgrids & Both & Both & Mgrids \\
\hline Users with meters & Mgrid & All & All & Mgrid & Mgrid \\
\hline Minimum 2 generators? & No & No & No & No & No \\
\hline Cost [US\$] & 33858 & 40344 & 33824 & 33224 & 39906 \\
\hline
\end{tabular}

The 5 top-ranked options were presented to the group of technical and social experts from the NGOs PA and ESF in order to they select the most appropriate. The experts based their decisions on very specific details of the community. First they determined wind resource variability in the area could lead the community to several days without energy (even for the higher autonomy demand scenario). Second the available budget was very limited, so implementing one of the most expensive solutions could entail limitations when electrifying the remaining consumption points. Third the risk of conflicts between users if electrifying through microgrids was considered higher than the potential social benefits of these configurations. In conclusion, the option "PV individual" was chosen for the North and South Parts and a 95 W PV panel was installed at each of the 22 target households.

To complete the design of the electrification system, the remaining 17 households and the 2 shops were analyzed. The experts determined their geographical dispersion was higher and their wind resource lower than for the North and South Parts, so microgrids and wind technology were discarded. Thus a $95 \mathrm{~W}$ PV panel was installed at each consumption point. Therefore, the total cost for the 39 households and the 2 shops was $\$ 63099$.

\subsection{Additional remark}

As observed the cost of the project was: $\$ 21836$ for the two wind microgrids (Stage 1); \$13341 for the micro-hydro power plant (Stage 2); \$12699 for the solar microgrid (Stage 3); and \$63099 for the individual solar systems (Stage 4). That is a total global cost of $\$ 110975$. In order to have a magnitude order about the cost of the proposed solution, the cost of installing an individual solar system at each consumption point was calculated; which is a commonly utilized solution due to its technical simplicity. The obtained cost was $\$ 104585$. When comparing both solutions, the costs are very similar; being the implemented solution just a $6 \%$ more expensive than the common solution. However, the implemented solution uses the most appropriate technology for each point, greatly responding to users' real needs. In particular the high wind resource in an area of the community is used to install two wind microgrids that allow good development opportunities to the connected users (Kirubi et al., 2009). For the school and the health center, which are key points for the population, microgrids are also installed, allowing punctual demand increases and ensuring a good reliability in their supply: for the school a hydroelectric power plant offers a continuous electric service, while for the health center several PV panels are installed so if one fails the others still supply the electricity. Finally, in the remaining scattered points, individual systems are implemented since microgrids would be too expensive and bad 
relationships between users do not favor their use. In this way the most adequate option is installed at each consumption point improving the sustainability of the project and users' appropriateness of the electrification systems. Moreover, the slight cost difference reinforces that the use of a combination of technologies is not an economical handicap for the community.

\section{Evaluation and results}

In December 2012, after 25 months since the end of the project implementation in the community of Alto Peru, an ex-post evaluation was carried out in order to analyze the sustainability and the population satisfaction with the adopted solution. In general, most of the population was satisfied with the quality of the electric service. However, although designing this project as a combination of technologies proved to be the best option in terms of technical efficiency, it also resulted in some inconveniences because of the diversity of options.

First, due to the great variability of the wind resource some disagreements between families electrified in Stage 1 appeared. For example, the users from one wind microgrid punctually had less energy than the users from the other one and, consequently, their paying willingness decreased. Therefore, the installation of two extra PV panels in this microgrid was decided, preventing from the risk of project failure that this fact could imply. Besides, the available electricity for the wind microgrids' users (Stage 1) was much more variable than for the PV systems (Stages 3 and 4). Although wind users were satisfied with their service, some of them stated that they would have preferred the PV technology in order to have a more constant electric supply. Otherwise, the WT had some mechanical problems and reveled to be a less reliable technology than expected. Taking into account that Alto Peru was located in a remote area of the Andean highlands, the repair of broken WT was slow and expensive, being necessary to transport the turbine to the nearest city and then back to the community. Unfortunately, this reinforced users' preference on PV technology instead of WT.

Second, the electric meters used in the implementation of the system only measured the consumption without limiting it, since the limiting devices are currently an expensive and nonnational technology that creates external dependencies and requires of technicians for their scheduling. Therefore, based on previous experiences, a consumption control strategy according to the tariff was established: the more you consume, the more you proportionally pay. However, this strategy did not resulted enough and, for example, in the PV microgrid (Stage 3) the health center and the 2 restaurants normally used more energy what corresponded, impeding the 2 households to use the energy they needed. To counteract this problem, the NGO PA established a training program to sensitize microgrids users about the need of arranging between them to adequately share the available electricity. However, when writing this paper, no consensus was still met, so some microgrid users stated that they would have preferred individual systems.

Third, while individual PV systems only provided electricity for domestic uses, microgrids allowed developing other activities at good resource periods. In particular while the micro-hydro power plant allowed realizing some productive activities (Stage 2), the individual PV systems (Stage 4) limited some activities as, for example, the case of a cheese producer who could not improve his business. 
Fourth, the lack of a renewable energy market in the region of Cajamarca implied that technicians depended on distributors located in the capital of the country (Lima). This was a huge barrier for maintaining and repairing the broken equipment autonomously, even more considering that different technologies were utilized. Thus, after two years since the end of the project implementation, Alto Peru's population still depended on PA's technicians when technical problems occur.

Due to all of these factors, although the implemented solution was technically and economically efficient, it presented some inconveniences. For future projects, more factors must be taken into account, and special trainings and sensitizing strategies must be implemented for reducing the mentioned inconveniences, even though this will imply stronger efforts for the technicians in charge of the project and, consequently, a higher cost of the projects. First, the whole community will have to be involved in the design and the decision-making processes must be participatory and equitable to ensure the adopted solution will really respond to the local context and needs. In particular, all the collectives of the community shall be represented in order to respond to the needs of all of them, fitting out special spaces mainly for collectives as women or children that tend to be disregarded. Second, a specific training program will be needed, not only depending on the different technologies, but also on the configuration of the electric distribution (individual systems or microgrids), to warranty that all users are aware about their responsibilities in terms of energy management. In the case of individual systems, the training should focus the appropriate management of a limited amount of energy, while in the case of microgrids it should focus an adequate distribution of energy between users, avoiding one user consumes more than expected leaving the other without enough energy. Third, diversity in terms of technology and local energy resources might introduce punctual inequities, and must be correlated with the different needs and socioeconomic diversity of the population, ensuring the design will satisfy their needs and minimize social conflicts. This will imply a previous training process, so that future users will be capable to participate in the planning process and decide which technology they prefer on a reasoned base. Finally, additional training will be needed to strengthen the link between local operators and supply distributors in Peru, so that any problem can be solved without needing PA intervention, thus strongly improving autonomy and sustainability at the medium and long terms.

\section{Conclusions}

This paper describes the technical design of the electrification project of Alto Peru (Cajamarca, Peru). This was a unique experience combining different technologies inside a community, according to micro-sale energy resources and the social characteristics of population. Through this system, 58 households, 2 shops, 2 restaurants, a health center, a school and church were electrified in four stages: two wind microgrids, a micro-hydro power plant, a PV microgrid and individual PV systems.

When selecting the best technical and social electrification option, the available energy resources were analyzed. Therefore in highlands wind energy was used, in the presence of a waterfall a micro-hydro power plant was implemented and in lowlands scattered from the wind solar energy was utilized. Moreover microgrids were used (or not) depending on weather social conflicts among the connected families do not exist (or exist). Besides, while for the micro-hydro power plant and the PV microgrid the design was not excessively hard, for the wind microgrids and the 
individual PV systems, which supply to a higher amount of consumption points, the design was more complex. For this purpose a two-step process was carried out. First several electrification options were generated with two mathematical models taken from the literature and then the results were presented to a group of experts in order to they choose the best option. In the case of the individual PV systems, where a greater amount of electrification options were generated, a multicriteria decision-making process was used to reduce the group of options before presenting them to the group of experts.

After some months since the implementation of the project, an evaluation of the performance of the system was carried out. It was seen that, even though the system was technically efficient, some differences in the electricity availability between users (due to the different technologies used) caused some disagreements in the population. Therefore it was concluded that for future projects more training processes will be necessary for ensuring that the design and implementation of the electrification system really responds to the real needs of population.

Finally it should be highlighted that the current research has proven that it would be interesting to emphasize on multicriteria decision-making processes for future projects, in order to design electrification systems considering a higher amount of design criteria and the points of view of all the stakeholders involved in the project. As future research, the authors are developing a decision-aid tool that allows rural electrification promoters to design socially adapted projects. In particular the design process is divided in three decision levels, ordered according to the importance of the decisions taken, and considers the point of view of all the stakeholders involved in the project as well as economic, technical and social aspects.

\section{Acknowledgements}

This paper was supported by the Spanish MICINN project ENE2010-15509 and co-financed by FEDER and by the Centre for Development Cooperation of the Technical University of Catalonia (UPC). The authors are very grateful for all the assistance and support provided by the NGOs Practical Action (Peru), Engineering Without Borders (Catalonia, Spain), and Green Empowerment (USA).

\section{References}

Akorede, M.F., Hizam, H., Pouresmaeil, E., 2010. Distributed energy resources and benefits to the environment. Renew. Sustain. Energy Rev. 14, 724-734.

Amador, J., Dominguez, J., 2005. Application of geographical information systems to rural electrification with renewable energy sources. Renew. Energy 30, 1897-1912.

Bakos, G.C., 2002. Feasibility study of a hybrid wind/hydro power-system for low-cost electricity production. Appl. Energy 72, 599-608.

Bekele, G., Tadesse, G., 2012. Feasibility study of small hydro/PV/wind hybrid system for off-grid rural electrification in Ethiopia. Appl. Energy 97, 5-15.

Cavallaro, F., Ciraolo, L., 2005. A multicriteria approach to evaluate wind energy plants on an Italian island. Energy Policy 33, 235-244.

Chaurey, A., Ranganathana, M., Mohanty, P., 2004. Electricity access for geographically disadvantaged rural communities - technology and policy insights. Energy Policy 32, 1693-1705.

Coello, J., Escobar, R., Dávila, C., Villanueva, G., Chiroque, J., 2006. Micro hydro power plants and other alternative energies: contributions of practical action - ITDG to rural development. Environmental case studies and white/technical papers. Port of Entry, Environmental Business Network for the Americas. 
Department for International Development (DFID), 2002. Energy for the poor. Underpinning the Millennium Development Goals, London.

Deshmukh, M.K., Deshmukh, S.S., 2008. Modeling of hybrid renewable energy systems. Renew. Sustain. Energy Rev. 12, 235-249.

Domenech, B., Ferrer-Martí, L., Pastor, R., 2012. Diseño de sistemas aislados de electrificación rural con consideraciones técnicas y sociales. $6^{\text {th }}$ Int. Conf. Ind. Eng. Ind. Manag. Vigo, Spain.

Dorji, T., Urmee, T., Jennings, P., 2012. Options for off-grid electrification in the Kingdom of Bhutan. Renew. Energy 45, 51-58.

El-Shatter, T.F., Eskander, M.N., El-Hagry, M.T., 2006. Energy flow and management of a hybrid wind/PV/fuel cell generation system. Energy Convers. Manag. 47, 1264-1280.

Ferrer-Martí, L., Pastor, R., Capó, G.M., Velo, E., 2011. Optimizing microwind rural electrification projects. A case study in Peru. J. Glob. Optim. 50, 127-143.

Ferrer-Martí, L., Garwood, A., Chiroque, J., Ramirez, B., Marcelo, O., Garfí, M., Velo, E., 2012. Evaluating and comparing three community small-scale wind electrification projects. Renew. Sustain. Energy Rev. 16, 5379-5390.

Ferrer-Martí, L., Domenech, B., García-Villoria, A., Pastor, R., 2013. A MILP model to design hybrid windphotovoltaic isolated rural electrification projects in developing countries. Eur. J. Oper. Res. 226, 293-300.

Frearson, L., Tuckwell, M., 2013. The future of mini-grids: from low cost to high value. Using demand driven design to maximise revenue and impact. Asian Development Bank, Manila.

Giatrakos, G.P., Tsoutsos, T.D., Mouchtaropoulos, P.G., Naxakis, G.D., Stavrakakis, G., 2009. Sustainable energy planning based on a stand-alone hybrid renewable energy/hydrogen power system: Application in Karpathos Island, Greece. Renew. Energy 34, 2562-2570.

Gueymard, C.A., Wilcox, S.M., 2011. Assessment of spatial and temporal variability in the US solar resource from radiometric measurements and predictions from models using ground-based or satellite data. Sol. Energy 85, 1068-1084.

Henao, F., Cherni, J.A., Jaramillo, P., Dyner, I., 2012. A multicriteria approach to sustainable energy supply for the rural poor. Eur. J. Oper. Res. 218, 801-809.

International Energy Agency (IEA) 2013. World Energy Outlook, Paris.

Kanagawa, M., Nakata, T., 2008. Assessment of access to electricity and the socio-economic impacts in rural areas of developing countries. Energy Policy 36, 2016-2029.

Kenfack, J., Neirac, F.P., Tatietse, T.T., Mayer, D., Fogue, M., Lejeune, A., 2009. Microhydro-PV-hybrid system: Sizing a small hydro-PV-hybrid system for rural electrification in developing countries. Renew. Energy 34, 2259-2263.

Kirubi, C., Jacobson, A., Kammen, D.M., Mills, A., 2009. Community-Based Electric Micro-Grids Can Contribute to Rural Development: Evidence from Kenya. World Dev. 37, 1208-1221.

Kumar Lal, D., Bhusan Dash, B., Akella, A.K., 2011. Optimization of PV/wind/micro-hydro/diesel hybrid power system in HOMER for the study area. Int. J. Elec. Eng. Inform. 3, 307-325.

Lambert, T.W., Hittle, D.C., 2000. Optimization of autonomous village electrification systems by simulated annealing. Sol. Energy 68, 121-132.

Leary, J., While, A., Howell, R., 2012. Locally manufactured wind power technology for sustainable rural electrification. Energy Policy 43, 173-183.

Loken, E., 2007. Use of multicriteria decision analysis methods for energy planning problems. Renew. Sustain. Energy Rev. 11, 1584-1595.

Meteosim Truewind SL, Latin Bridge Business SA. Peru Wind Atlas. Lima, Peru; 2008. Available at: http://dger.minem.gob.pe/AtlasEolico/atlaseolicolibro/presentacion.pdf.

Ministry of Energy and Mines (MINEM). Informe anual de gestión. Lima, Peru; 2008.

NASA. Surface meteorology and Solar Energy, Release 6.0. http://eosweb.larc.nasa.gov/sse/. Last access: $27^{\text {th }}$ March 2012.

National Institute of Statistics and Informatics (INEI). La pobreza en el Perú el año 2007. Lima, Peru; 2007.

Nema, P., Nema, R.K., Rangnekar, S., 2009. A current and future state of art development of hybrid energy system using wind and PV-solar: A review. Renew. Sustain. Energy Rev. 13, 2096-2103.

Nieuwenhout, F.D.J., Van Dijk, A., Lasschuit, P.E., Van Roekel, G., Van Dijk, V.A.P., Hirsch, D., Arriaza, H., Hankins, M., Sharma, B.D., Wade, H., 2001. Experience with solar home systems in developing countries: A review. Prog. Photovolt.: Res. Appl. 9, 455-474.

Nijkamp, P., Reitveld, P., Voogd, H., 1990. Multicriteria evaluation in physical planning, Elsevier Science, North Holland, Amsterdam. 
Pohekar, S.D., Ramachandran, M., 2004. Application of multi-criteria decision making to sustainable energy planning - A review. Renew. Sustain. Energy Rev. 8, 365-381.

Ramirez, B., Mantilla, W., 2009. Diagnóstico socioeconómico del caserío de Alto Perú, Practical Action, Cajamarca, Peru.

Ranaboldo, M., Ferrer-Martí, L., Velo, E., 2014. Micro-scale wind resource assessment for off-grid electrification projects in rural communities. A case study in Peru. Int. J. Green Energy 11, 75-90.

Rolland, S., Glania, G., 2011. Hybrid mini-grids for rural electrification: Lessons learned. Alliance for Rural Electrification, Brussels.

Saheb-Koussa, D., Haddadi, M., Belhamel, M., 2009. Economic and technical study of a hybrid system (windphotovoltaic-diesel) for rural electrification in Algeria. Appl. Energy 86, 1024-1030.

Tenenbaum, B., Greacen, C., Siyambalapitiya, T., Knuckles, J., 2014. From the bottom up - How small power producers and micro-grids can deliver electrification and renewable energy in Africa, The World Bank, Washington.

Wang, J.J., Jing, Y.Y., Zhang, C.F., Zhao, J.H., 2009. Review on multi-criteria decision analysis aid in sustainable energy decision-making. Renew. Sustain. Energy Rev. 13, 2263-2278.

Wamukonya, N., Davis, M., 2001. Socio-economic impacts of rural electrification in Namibia: comparisons between grid, solar and unelectrified households. Energy Sustain. Dev. 5, 5-13.

Yadoo, A., Cruickshank, H., 2012. The role for low carbon electrification technologies in poverty reduction and climate change strategies: A focus on renewable energy mini-grids with case studies in Nepal, Peru and Kenya. Energy Policy 42, 591-602.

Zahedi, A., 2006. Solar photovoltaic (PV) energy; latest developments in the building integrated and hybrid PV systems. Renew. Energy 31, 711-718.

Zhou, P., Ang, B.W., Poh, K.L., 2006. Decision analysis in energy and environmental modeling: An update. Energy 31, 2604-2622.

Zhou, W., Lou, C., Li, Z., Lu, L., Yang, H., 2010. Current status of research on optimum sizing of stand-alone hybrid solar-wind power generation systems. Appl. Energy 87, 380-389. 